\title{
PROJETO “NÁRNIA"
}

Cinthya K. Ramos ${ }^{1}$

\section{RESUMO}

Este trabalho é o resultado de um programa arqueológico desenvolvido para a disciplina Fundamentos da Prática Arqueológica. O objetivo do programa é realizar a simulação de uma escavação, abordando todas as etapas de um trabalho de campo: da definição de um sítio arqueológico, dos procedimentos de prospecção da área e da aplicação das técnicas de escavação, até a formação de um registro arqueológico passível de análise laboratorial. Para a realização dessa simulação, abordamos um sítio arqueológico artificial (Nárnia), onde trabalhamos com a questão da modificação de um espaço para a adaptação das necessidades humanas.

Palavras-chave: fundamentos; arqueologia; escavação; paisagem; prática arqueológica.

\section{ABSTRACT}

This work is the result of an archaeological program developed for the discipline Fundamentals of Archaeological Practice. The program's goal is to perform the simulation of an excavation, covering all stages of field work: the definition of an archaeological site, the survey procedures of the area and the application of excavation techniques, until the formation of an archaeological record subject to laboratory analysis. To carry out this simulation, we approach an artificial archaeological site (Narnia), where we work with the issue of modifying a space for the adaptation of human needs.

Keywords: grounds; archeology; excavation; landscape; archaeological practice.

\section{RESUMEN}

Este trabajo es el resultado de un programa arqueológico desarrollado para la disciplina Los Fundamentos de la práctica arqueológica. El objetivo del programa es llevar a cabo la simulación de una excavación, que cubre todas las etapas del trabajo de campo: la definición de un sitio arqueológico, los procedimientos de inspección de la zona y la aplicación de técnicas de excavación, hasta la formación de un registro arqueológico sujeto a análisis de laboratorio. Para llevar a cabo esta simulación, nos acercamos a un sitio arqueológico artificial (Narnia), donde trabajamos con el tema de la modificación de un espacio para la adaptación de las necesidades humanas.

\footnotetext{
1 Professora de História da Secretaria da Educação do Estado de São Paulo. Pós-graduanda do Programa de Arqueologia, História e Sociedade da Universidade de Santo Amaro - UNISA.
} 


\section{Revista de Arqueologia Pública}

Palabras clave: terreno; arqueología; excavación; paisaje; la práctica arqueológica.

\section{INTRODUÇÃO}

A espécie humana sobrevive há milhares de anos fazendo a adaptação do meio ambiente às suas necessidades, conforme o tempo. Houve uma época em que tudo o que o homem precisava era de um pequeno espaço para se assentar, um rio limpo e próximo de onde retirar água, e de uma área onde ele pudesse cultivar seu próprio alimento.

As necessidades humanas, no entanto, foram crescendo à medida em que a população e o contato com a tecnologia aumentaram. Logo, o espaço tornou-se escasso, a água canalizada e o alimento produzido em grande escala dentro de grandes indústrias.

O meio fora, então, adaptado, como o seria diversas vezes mais.

[...] O homem intervém, modela, dá forma a elementos do meio físico, segundo propósitos e normas culturais. Essa ação, portanto, não é aleatória, casual, individual, mas se alinha conforme padrões, entre os quais se incluem os objetivos e projetos. Assim, o conceito pode tanto abranger artefatos, estruturas, modificações da paisagem, como coisas animadas (uma sebe, um animal doméstico), e, também, o próprio corpo, na medida em que ele é passível desse tipo de manipulação (deformações, mutilações, sinalações) ou, ainda, os seus arranjos espaciais (um desfile militar, uma cerimônia litúrgica) (MENEZES, 1983:112).

A Arqueologia é uma ciência que, por meio da cultura material, procura entender o homem e suas relações sociais, compreendendo as transformações culturais da sociedade. Dessa forma, a ciência arqueológica adquire autonomia quando the é aplicada uma metodologia de trabalho. É importante que encaremos a disciplina além da prática de campo e the atribuamos um caráter interdisciplinar, uma ciência que dialoga com outras diversas para alcançar seu objetivo de estudo (FUNARI, 1988).

Em outras palavras, também a Arqueologia estuda os sistemas sócio-culturais, sua estrutura, seu funcionamento e seu comportamento ao longo do tempo, sua mudança. A particularidade está em que, para essas operações, ela conta exclusiva ou preponderantemente com informação derivada dos restos materiais - a cultura material (MENEZES, 1983:113).

Foi seguindo esta linha de pensamento que iniciamos os trabalhos no Sítio Arqueológico Nárnia. Localizado num pequeno bairro da zona norte de São Paulo, o sítio está inserido em uma das construções mais antigas da região oeste do bairro, área de intensa ocupação humana.

Em um trabalho de prospecção previamente feito no entorno do sítio, percebemos grande quantidade de material arqueológico aparentemente fora do contexto "QUARTO", como foi classificada a área de escavação. Procuramos investigar o tipo de ocupação que havia no local, partindo da premissa de que a área era uma região residencial, de acordo com fontes documentais recuperadas no cartório da cidade. 


\section{Revista de Arqueologia Pública}

Nosso objetivo é perceber os rumos de ocupação humana que a área tomou com o tempo: tornou-se uma ocupação temporária? Um local de ritual? Uma área de descarte?

Para isso, delimitamos a área de escavação do QUARTO à região oeste, onde uma prospecção revelou uma área, aqui denominada GUARDA ROUPA DE NÁRNIA, como uma área bastante promissora para o resgate de vestígio material.

\section{GEORREFERENCIAMENTO DO SÍTIO NÁRNIA}

O Sitio Arqueológico Nárnia está localizado na zona norte da cidade de São Paulo, à rua Carolina Bauer, número 146, bairro do Imirim.

A rua Carolina Bauer é uma rua residencial, cuja numeração vai do número 34 ao 180 . Segundo relatos coletados pela equipe de prospecção por meio de entrevistas com seus moradores mais antigos, até os anos 1950 a rua Carolina Bauer era conhecida como rua Heloísa, e fora uma das primeiras do bairro a ser construída dentro de um novo contexto de modernização da região.

Conhecido como "Terra de Índios" devido sua grande quantidade de população indígena, o bairro do Imirim recebeu uma igreja cristã, duas avenidas principais (Avenida Engenheiro Caetano Álvares e Avenida Imirim) que o ligam aos outros bairros, e uma famosa, hoje extinta, linha de ônibus que ligava a zona norte a zona sul de São Paulo, a linha Imirim-Itaim. Assim o bairro foi sendo adaptado às novas necessidades.

Apesar de as casas mais antigas datarem dos anos 1950-60, a presença de uma chácara no entorno do número 146 indica que a região é bem mais antiga, provavelmente datável entre meados do século XIX e início do século XX, quando os moradores do Imirim eram imigrantes portugueses e italianos, donos de pequenas propriedades agrícolas.

Para iniciar nossos trabalhos, dividimos a rua Carolina Bauer em lotes. Escolhemos o de número 146 para iniciar as escavações, uma vez que essa é uma das primeiras áreas ocupadas da rua.

Analisando a planta original do lote, partindo do que já conhecemos de construções do século $X X$, poderíamos inferir que o lote fora construído com a intenção de ser uma estrutura residencial. Seu interior possuía seis divisões de concreto que poderiam, um dia, ter funcionado como paredes separando cômodos. Assim, para não cairmos na armadilha da indução (NEUSTUPNÝ, 1993), deslocamos uma equipe de levantamento documental até o Cartório da Subprefeitura da Cachoeirinha, a fim de resgatar algum tipo de documentação que comprovasse ou refutasse a hipótese.

No cartório, foi resgatado o registro de compra de um terreno na rua Heloísa, em 1947, por José Maria dos Santos Ramos.

A planta original do terreno é reproduzida a seguir: 


\section{Revista de Arqueologia Pública}

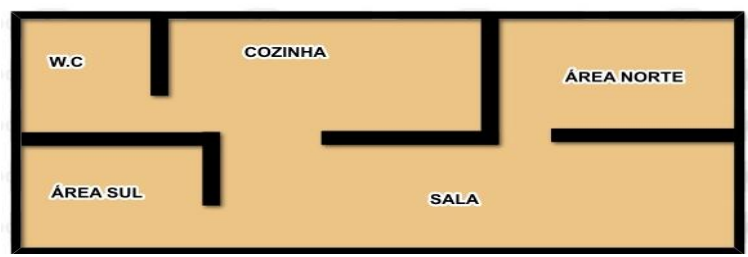

Figura 1 - Planta original do lote 146

Logo ficou evidente que nos últimos 65 anos o lote 146 passou por algumas modificações em sua estrutura.

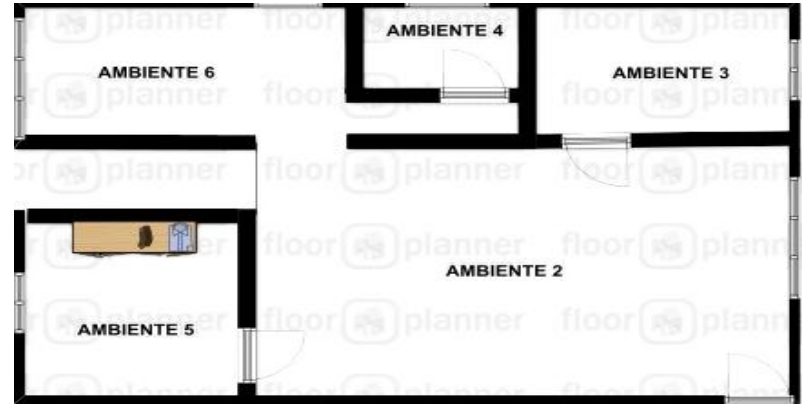

Figura 2 - Planta atual do lote 146

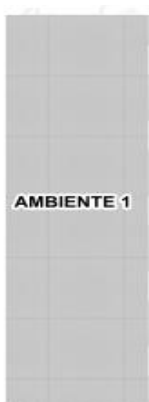

\section{LOCALIZAÇÃO DO SÍTIO NÁRNIA}

A área de escavação foi escolhida a partir de uma prospecção arqueológica que mostrou maior concentração de vestígios materiais humanos na área sul do lote 146. Chamaremos essa área dentro do lote de QUARTO (Fig. 3), antigo Ambiente 5, porque parte da cultura material resgatada durante a prospecção revelou ser característica de um dormitório. Dependendo das análises e resultados dessa escavação, poderemos definir se a abertura de uma outra área de escavação é necessária. 


\section{Revista de Arqueologia Pública}

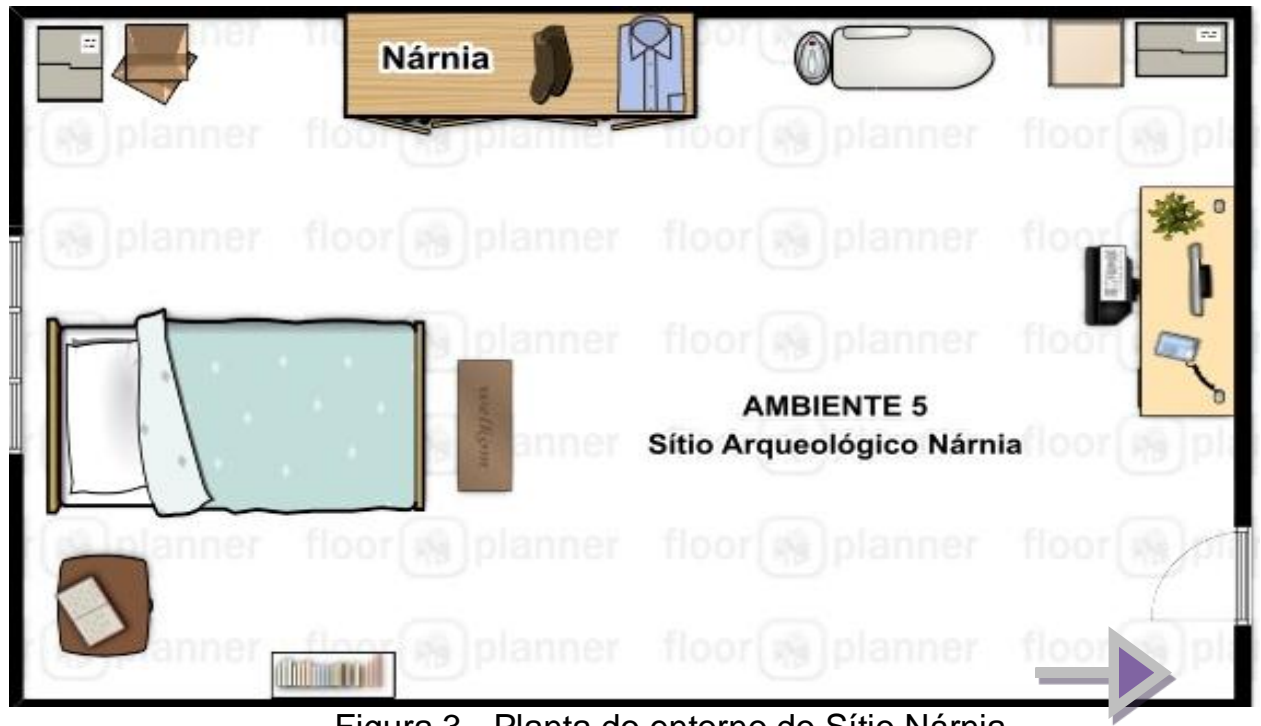

Figura 3 - Planta do entorno do Sítio Nárnia

\section{PROSPECÇÃO}

Os materiais recolhidos durante o trabalho de prospecção mostraram-se de tipos e funções diversos, em grande parte não relacionados com o ambiente "dormitório". Admitiu-se a possibilidade do QUARTO ter sido um ambiente usado como local de descarte de material, ainda que os objetos não mantivessem o padrão de concentração num só local, mesmo levando em conta a questão do deslocamento do depósito.

Antes de passar para a análise do material, no entanto, faremos um breve registro dos artefatos recolhidos no entorno do sítio:

\begin{tabular}{|l|l|}
\hline \multicolumn{1}{|c|}{ A Norte } & \multicolumn{1}{c|}{ A Sul } \\
\hline - uma escrivaninha & - um aparelho de som com vitrola \\
- um ventilador & - uma máquina de escrever antiga \\
- um cesto de plástico & - duas pastas arquivo \\
- uma cadeira de madeira & - um par de tênis gasto \\
- porta canetas & - um cabo de vassoura \\
- aparelho de telefone & - uma cama \\
- aparelho celular & \\
- máquina fotográfica & \\
- três caixas arquivo & \\
- uma flâmula & \\
- um pacote de ração para cachorro & \\
- uma tábua de passar roupas & \\
\hline
\end{tabular}

Tabela 1 - Registro dos artefatos do entorno do sítio 


\section{Revista de Arqueologia Pública}

\section{o síTIO}

$\mathrm{Na}$ limitação oeste do QUARTO, encontrou-se uma região onde o material estava mais organizadamente disposto e concentrado. Essa organização promoveu um panorama dos objetos em relação ao contexto dormitório. Decidimos iniciar nossos trabalhos nessa região, que chamaremos "Nárnia".

Área de escavação - X: 1,8m; Y: 2,05m; Z: 0,47m.

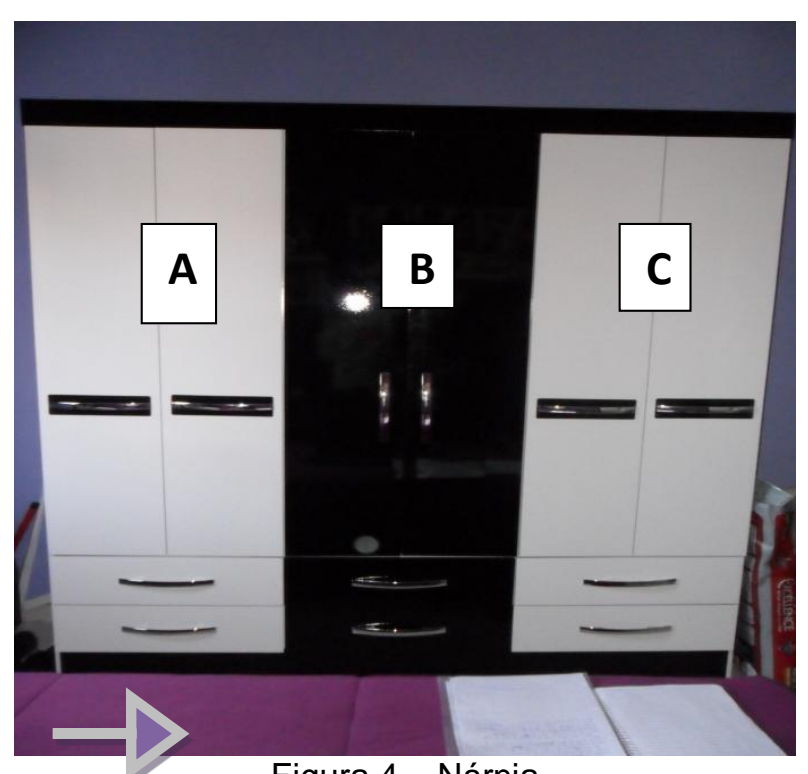

Figura 4 - Nárnia

\section{PREPARANDO A ESCAVAÇÃO}

Quadra A - A trincheira "A" foi dividida em três quadrículas de $0,49 \mathrm{~cm} \times 0,6 \mathrm{~cm}$, e duas de $0,18 \mathrm{~cm} \times$ 0,6cm. Essa divisão tinha por motivo o recolhimento do maior número de material possível. Possivelmente, esta é a quadra com o maior número de artefatos não relacionados ao contexto dormitório.

Quadra B - A trincheira "B" foi dividida em apenas três quadrículas diante da perspectiva de um menor número de artefatos a ser encontrados (percebido através da prospecção). Em todas as trincheiras foi usada a técnica de escavação por decapagem, a fim de observar ao mesmo tempo os estratos verticais e horizontais e, como consequência, melhor analisar a continuidade da ação humana no local (FUNARI, 1988: 65).

Quadra C - A trincheira "C" tem quatro quadrículas, seguindo a mesma perspectiva de recolhimento de pouco material da quadra "B". O curioso dessa quadra é que nela foram encontradas evidências materiais humana e animal, inclusive em seu entorno. 
Revista de Arqueologia Pública

\begin{tabular}{|c|c|c|c|}
\hline & QUADRA A & QUADRA B & QUADRA C \\
\hline Quadrícula 1 & $\begin{array}{l}X: 0,49 \mathrm{~m} \\
Y: 0,6 \mathrm{~m} \\
Z: 0,45 \mathrm{~m}\end{array}$ & $\begin{array}{l}X: 0,49 \mathrm{~m} \\
Y: 0,6 \mathrm{~m} \\
Z: 0,45 \mathrm{~m}\end{array}$ & $\begin{array}{l}\mathrm{X}: 0,4 \mathrm{~m} \\
\mathrm{Y}: 0,6 \mathrm{~m} \\
\mathrm{Z}: 0,45 \mathrm{~m}\end{array}$ \\
\hline Quadrícula 2 & $\begin{array}{l}X: 0,49 \mathrm{~m} \\
Y: 0,6 \mathrm{~m} \\
Z: 0,45 \mathrm{~m}\end{array}$ & $\begin{array}{l}\mathrm{X}: 0,18 \mathrm{~m} \\
\mathrm{Y}: 0,6 \mathrm{~m} \\
\mathrm{Z}: 0,45 \mathrm{~m}\end{array}$ & $\begin{array}{l}X: 1,05 \mathrm{~m} \\
Y: 0,6 \mathrm{~m} \\
Z: 0,45 \mathrm{~m}\end{array}$ \\
\hline Quadrícula 3 & $\begin{array}{l}X: 0,49 \mathrm{~m} \\
Y: 0,6 \mathrm{~m} \\
Z: 0,45 \mathrm{~m}\end{array}$ & $\begin{array}{l}X: 0,18 \mathrm{~m} \\
Y: 0,6 \mathrm{~m} \\
Z: 0,45 \mathrm{~m}\end{array}$ & $\begin{array}{l}X: 0,18 \mathrm{~m} \\
Y: 0,6 \mathrm{~m} \\
Z: 0,45 \mathrm{~m}\end{array}$ \\
\hline Quadrícula 4 & $\begin{array}{l}X: 0,18 \mathrm{~m} \\
Y: 0,6 \mathrm{~m} \\
Z: 0,45 \mathrm{~m}\end{array}$ & -- & $\begin{array}{l}X: 0,18 \mathrm{~m} \\
Y: 0,6 \mathrm{~m} \\
Z: 0,45 \mathrm{~m}\end{array}$ \\
\hline Quadrícula 5 & $\begin{array}{l}\mathrm{X}: 0,18 \mathrm{~m} \\
\mathrm{Y}: 0,6 \mathrm{~m} \\
\mathrm{Z}: 0,45 \mathrm{~m}\end{array}$ & -- & -- \\
\hline
\end{tabular}

Tabela 2 - Dimensões das quadras e quadriculas abertas para escavação

\section{REGISTROS - CADERNO DE CAMPO}

Abaixo a relação de artefatos recolhidos em cada quadrícula. Em seguida, fizemos um trabalho de determinação do potencial de análise dos objetos para determinar o que poderia ser descartado da análise laboratorial.

\begin{tabular}{|c|c|c|c|}
\hline & QUADRA A & QUADRA B & QUADRA C \\
\hline Quadrícula 1 & $\begin{array}{l}\text { - caixa com } \\
\text { documentos velhos; } \\
\text { - caixa com peças de } \\
\text { jogos de tabuleiro; } \\
\text { - apostilas de cursos; } \\
\text { - jogos de tabuleiro; } \\
\text { - duas pelúcias; } \\
\text { - caixa vazia; } \\
\text { - um cosmético; } \\
\text { - sacolas de papelão; } \\
\text { - canudo de diploma }\end{array}$ & $\begin{array}{l}\text { - um roupão de } \\
\text { banho; } \\
\text { - } 04 \text { casacos; } \\
\text { - uma calça jeans; } \\
\text { - uma bermuda; } \\
\text { - duas calças de } \\
\text { pijama; } \\
\text { - } 07 \text { cabides; } \\
\text { - uma caixa de } \\
\text { sapatos vazia; } \\
\text { - um par de botas }\end{array}$ & $\begin{array}{l}\text { - } 2 \text { cobertores; } \\
\text { - um tubo de } \\
\text { desodorante em } \\
\text { spray }\end{array}$ \\
\hline
\end{tabular}


Revista de Arqueologia Pública

\begin{tabular}{|c|c|c|c|}
\hline Quadrícula 2 & - 13 camisetas & $\begin{array}{l}\text { - } 11 \text { peças de roupas } \\
\text { íntima; } \\
\text { - uma bandeira do } \\
\text { Brasil }\end{array}$ & $\begin{array}{l}\text { - } 10 \text { camisetas } \\
\text { (sendo duas de } \\
\text { manga longa, oito de } \\
\text { manga curta, uma } \\
\text { delas de time de } \\
\text { futebol); } \\
\text { - } 12 \text { cabides; } \\
\text { - um álbum de } \\
\text { fotografias; } \\
\text { - um calendário do } \\
\text { ano de 2012; } \\
\text { - um frasco de } \\
\text { medicamento } \\
\text { veterinário; } \\
\text { - um pedaço de } \\
\text { algodão }\end{array}$ \\
\hline Quadrícula 3 & $\begin{array}{l}\text { - quatro livros; } \\
\text { - cinco caixas (duas } \\
\text { com CDs e DVDs, } \\
\text { três com } \\
\text { eletroportáteis); } \\
\text { - um porta CDs; } \\
\text { - um rolo de papel de } \\
\text { presente }\end{array}$ & - 10 pares de meias & $\begin{array}{l}\text { - } 4 \text { conjuntos de } \\
\text { pijama }\end{array}$ \\
\hline Quadrícula 4 & - três shorts & -- & $\begin{array}{l}\text { - } 4 \text { toalhas de banho; } \\
\text { - uma toalha de rosto; } \\
\text { - um saco de } \\
\text { presentes }\end{array}$ \\
\hline Quadrícula 5 & $\begin{array}{l}\text { - três pôsteres; } \\
\text { - certificados e } \\
\text { diplomas de curso ; }\end{array}$ & & \\
\hline
\end{tabular}




\section{Revista de Arqueologia Pública}

\begin{tabular}{|l|l|l|l|}
\hline & $\begin{array}{l}\text { - uma bandeira de } \\
\text { time de futebol }\end{array}$ & -- & \\
\hline
\end{tabular}

Tabela 3 - Relação de artefatos escavados por quadrícula

\section{DETERMINAÇÃO DO POTENCIAL DE ANÁLISE}

Ainda em campo, o material arqueológico passou por uma triagem a fim de definirmos quais artefatos teriam potencial para ser analisados em laboratório, levando em conta o que esses artefatos teriam a dizer. Pensando no material recolhido no entorno do sítio, mantivemos o padrão de separação do material com menos características de "dormitório" encontrados em Nárnia, a fim de determinar suas possíveis funcionalidades naquele ambiente QUARTO.

Os documentos escritos relacionados abaixo trazem algumas informações sobre preferência e dados pessoais de um dos possíveis moradores da casa. Descartaremos de nossa análise as seguintes fontes documentais, pois elas não nos trazem novas informações sobre a ocupação da casa. Assim, foram descartados:

\begin{tabular}{|l|l|}
\hline A1 & os pôsteres \\
\hline A1 & as caixas com documentos \\
\hline A3 & os certificados e diplomas \\
\hline A5 & as apostilas \\
\hline A5 & os livros \\
\hline
\end{tabular}

Tabela 4 - Artefatos descartados

Os objetos "roupas" (A2, A4, B1, B2, B3, C2, C3), por terem função lógica, serão ensacados, classificados e armazenados para análise posterior, pois sua determinação não é imediata, com exceção das peças de pijamas retiradas das quadrículas B1 e C3. Outros objetos com funcionalidade bem definida também serão descartados, como:

\begin{tabular}{|c|l|}
\hline A1 & sacolas de papelão \\
\hline A5/C4 & papel/sacola de presente \\
\hline
\end{tabular}

Tabela 5 - Artefatos armazenados para análise posterior

Assim, ficou-se com:

\begin{tabular}{|l|l|}
\hline A1 & Jogos de tabuleiro \\
\hline A1 & Caixa com peças de jogos \\
\hline A1 & Pelúcias \\
\hline A1 & Cosmético \\
\hline A1 & Canudo de diploma \\
\hline
\end{tabular}


Revista de Arqueologia Pública

\begin{tabular}{|c|l|}
\hline B1 & Roupão de banho \\
\hline C1 & Edredom/cobertor \\
\hline C1 & Desodorante \\
\hline A5/B2 & Bandeiras de time de futebol e Brasil \\
\hline C2 & Álbum de fotografias \\
\hline C2 & Calendário \\
\hline C2 & Medicamento de uso veterinário \\
\hline C2 & Algodão \\
\hline A3 & Caixas com CDs, DVDs/porta CDs \\
\hline C4 & Toalhas de banho/rosto \\
\hline B1/C3 & Pijamas \\
\hline
\end{tabular}

Tabela 6 - Artefatos com potencial para análise

\section{ANÁLISE LABORATORIAL E DISCUSSÃO DOS RESULTADOS}

Retomando a discussão presente na introdução deste trabalho, por meio da análise das plantas original e atual da casa, percebemos que o imóvel foi modificado com o tempo, provavelmente adaptado às necessidades dos moradores primários, e daqueles que possivelmente vieram depois. É admissível pensar que a população da casa tenha aumentado, por isso a expansão do número de cômodos, embora essa hipótese só possa ser efetivamente trabalhada com a aplicação da escavação de depósitos estratigráficos, o que comprovaria a questão da ocupação sucessiva e a determinação das formas de ocupação do lugar em cada período (FUNARI, 1988: 57).

No Projeto Nárnia temos como objetivo delinear o que seria esse ambiente QUARTO. Como justificado na introdução deste projeto, a prospecção da superfície da área indicou que o cômodo poderia haver perdido a sua função de dormitório em algum momento nos últimos sessenta anos, desde a compra do terreno. Partindo de pressupostos anteriores, nossa meta foi analisar como a construção foi adaptada de acordo com as necessidades dos moradores do lote 146 ao longo do tempo. Sem conhecer as pessoas que habitaram o local desde a sua transformação em residência, pretendemos, através da cultura material, observar os padrões que determinaram o tipo de ocupação desse sítio.

Estudar os artefatos exige que os relacionemos ao contexto em que eles estão inseridos (FUNARI, 1988: 14-19). No caso dos artefatos retirados de Nárnia, esses objetos têm pouca ou nenhuma relação com o ambiente dormitório, o que nos indica a primeira pergunta: qual a relação desses objetos com o espaço em que estão inseridos? Eles foram colocados ali aleatoriamente ou sua organização (ou ausência de) tem um sentido, mesmo que inconsciente, dado pelas pessoas que passaram ali?

Consideramos que o número encontrado de material não característico de um dormitório foi maior do que o de material específico de um quarto de dormir. A primeira suposição que fizemos é a 


\section{Revista de Arqueologia Pública}

de que o local tornou-se, em algum momento, um depósito de material, um local de descarte de objetos não mais usados, ou usados com pouca frequência.

A modificação do espaço pode ter ocorrido em função do aumento da produção de cultura material. Percebemos na Tabela 1 que alguns dos objetos, especialmente o aparelho de som e a máquina de escrever, pareciam estar fora de uso ou até mesmo sem funcionar. Com a ascensão da era da tecnologia descartável do século XXI, é possível que esses objetos tenham sido substituídos por outros mais modernos, ou simplesmente deixaram de funcionar e foram depositados ali. O que se pode afirmar, no entanto, é que os objetos não foram descartados completamente. Podemos trabalhar com algumas hipóteses: 1) os objetos não foram descartados definitivamente por motivo de apego sentimental. Tanto a máquina de escrever quanto a vitrola tornaram-se, hoje, "peças de museu", e sua disponibilidade em lojas de eletroportáteis foi colocada de lado por aparelhos modernos como os computadores e reprodutores de novas mídias. É natural o sentimentalismo que alguns objetos causam nas pessoas, que se apegam a eles de maneira nostálgica e têm dificuldades em desfazer-se de tais materiais; e também, 2) os objetos foram reutilizados, ou seja, tiveram suas funções alteradas de acordo com as necessidades do(s) morador(es) do lote 146. Essa hipótese é possível quando observamos a forma como a vitrola e a máquina de escrever estavam dispostas no cenário, como mesas de apoio para as pastas de arquivo. É possível pensar, ainda, que as duas hipóteses se completem: ao mesmo tempo em que o sentimentalismo possa ter impedido o descarte total dos objetos, o(s) morador(es) encontraram nova função para eles, a fim de reaproveitá-los.

Em relação à análise desses objetos, especificamente, concentramo-nos nessas hipóteses como reafirmação de nosso objetivo inicial, que é entender a questão da modificação do espaço. Por isso, ao iniciarmos este trabalho, partimos da apresentação do georreferenciamento de Nárnia e da apresentação da história do bairro, a fim de demonstrar o processo de adaptação do meio.

Outros objetos no entorno de Nárnia ajudam a pensar o local como um depósito de material, uma vez que eles parecem não se relacionar. Por exemplo, a tábua de passar e o pacote de ração para cachorros um ao lado do outro; sobre a tábua de passar, um aparelho de telefone e uma máquina fotográfica (que, assim como a vitrola e a máquina de escrever, não podemos ter certeza se funcionam). E, ainda, um cabo de vassoura - apenas o cabo -, cuja função neste contexto parece deslocada.

Um dos aspectos de Nárnia que mais chamou a atenção foi o resgate de um frasco de remédio para otite animal em meio àquela quantidade imensa de objetos. O frasco, no entanto, ao contrário de outros artefatos, não aparece isolado. Muito próximo a ele, encontrou-se um pedaço de algodão. A partir daí conseguimos estabelecer uma ligação entre os dois objetos e o pacote de ração encontrado no entorno, e concluir que o lote 146 não só possuía um ou mais animais de estimação, como o medicamento estava em uso quando da última vez que fora colocado ali, considerando também que ele não fora fechado corretamente, como se estivesse em uso constante.

Esse pequeno detalhe nos abre uma nova possibilidade de interpretação: a de que Nárnia funcionava não só como um lugar para guardar roupas, mas também como um local de fácil acesso

\begin{tabular}{|l|l|l|l|l|l|l|}
\hline (C) Rev. Arqueologia Pública & Campinas, SP & v. 10 & n. 1 & p. 24-36 & MAR. 2016 & ISSN 2237-8294 \\
\hline
\end{tabular}




\section{Revista de Arqueologia Pública}

para o(s) habitante(s) de QUARTO para armazenar o que thes fosse de maior utilidade. Logo, sugerimos que Nárnia funcionava como um "armazém" para o próprio quarto, de certa forma; não um ambiente de descarte ou de armazenamento apenas do que é pouco ou nunca utilizado, mas um ambiente que possibilita o fácil acesso ao que era utilizado com frequência, portanto precisava estar ao alcance.

Mas podemos afirmar que a área perdeu completamente sua função de dormitório? Aproveitando as hipóteses aplicadas à análise dos vestígios materiais, podemos aplicar a mesma metodologia e implicar que, assim como alguns dos objetos ali dispostos, a área poderia ter apenas adquirido uma nova função, sem perder sua qualidade original, mas adaptando-se à necessidade de uma área onde objetos que são pouco ou nunca usados pudessem ser armazenados para dar espaço a novos objetos em outros ambientes da casa. Vamos lembrar que, embora sem organização sistemática dos objetos, tanto os que estavam no interior de Nárnia, quanto os de seu entorno, possuíam uma espécie de "arrumação desarrumada". Muitos dos objetos não tinham ligação entre si, mas estavam assentados de forma ordeira, como se tivessem sido depositados ali com um objetivo (DREWETT, 2011, p. 17-21). Além disso, a presença de uma cama no entorno do sítio é o que mais caracteriza o uso do cômodo como dormitório. Não podemos esquecer, também, que foram coletados, no total, dez peças de pijamas em duas quadrículas diferentes e dois cobertores numa terceira quadrícula. Assim, os pijamas e cobertores escavados em Nárnia se articulam muito melhor com o ambiente, e indicam que o lugar poderia ter sido usado como dormitório, mas não exclui a possibilidade de esse uso ter sido concomitante com outras maneiras de utilizar o espaço.

Em nossa análise dos resultados obtidos, praticamente foi excluída a hipótese do ambiente ter funcionado como uma área de ritual religioso em qualquer momento. Não foi encontrado qualquer indício ou objeto que remeta religiosidade por parte de quem habitou aquela região.

\section{CONSIDERAÇÕES FINAIS}

Depois que os materiais descartados foram devidamente classificados e registrados, e os objetos com potencial de análise enviados ao laboratório e discutidos, conseguimos estabelecer algumas considerações.

Ao iniciarmos este trabalho, a abordagem do georreferenciamento do Sítio Arqueológico Nárnia não foi aleatória, tampouco tinha como único objetivo apontar a localização do sítio. Essa abordagem também visava resgatar a história do bairro onde Nárnia está localizada, como forma de estabelecer a primeira ideia de modificação e adaptação do espaço.

Partimos da premissa de que nossa área de escavação também passou por um processo de modificação e adaptação do ambiente de acordo com as necessidades dos moradores no decorrer do tempo. Nossas indagações acompanhavam nos rumos que a ocupação humana na área tomou.

Para isso, iniciamos as escavações em uma área denominada QUARTO, admitindo que a região poderia ter como função o local de descarte de material. Essa possibilidade foi levantada pela

\begin{tabular}{|l|l|l|l|l|l|l|}
\hline (C) Rev. Arqueologia Pública & Campinas, SP & v. 10 & n. 1 & p. 24-36 & MAR. 2016 & ISSN 2237-8294 \\
\hline
\end{tabular}




\section{Revista de Arqueologia Pública}

observação da área, quando notou-se que alguns objetos de característica de dormitório, como uma cama e um guarda-roupa, faziam parte do ambiente, mas em companhia de outros vestígios completamente diversos de um contexto entendido como "quarto de dormir", como uma tábua de passar e um cabo de vassoura, por exemplo.

O guarda-roupa tornou-se nossa principal área de escavação, recebendo o nome de "Nárnia". Em Nárnia, mais um conjunto de objetos fora do contexto 'quarto' foram escavados, fortalecendo nossa primeira hipótese de que o QUARTO sofrera modificações e, além de dormitório, passou a funcionar como área de descarte. No entanto, um outro tipo de cultura material também foi resgatado em Nárnia: dez peças de pijamas e dois cobertores.

O fácil acesso que Nárnia permitia a determinados objetos, como um remédio para otite animal e documentos pessoais, nos levou a conclusão de que Nárnia servia de armazém para o próprio QUARTO que, por sua vez, era possivelmente o, ou um dos locais de depósito do lote 146.

Isso não quer dizer, contudo, que o QUARTO perdera completamente sua função de dormitório. Pelo contrário, a presença da cama e dos pijamas reforça a hipótese de que o local possuía as duas funções concomitantemente.

\section{REFERÊNCIAS BIBLIOGRÁFICAS}

DREWETT, P. L. Field Archaeology: An Introduction. USA: Ed. Taylor \& Francis, 2011. p. 17-21.

FUNARI, P. P. Arqueologia. São Paulo: Editora Ática, 1988. Série Princípios.

MENESES, U. T. B. A cultura material no estudo das sociedades antigas. In: I Simpósio Nacional de História Antiga (Universidade Federal da Paraíba), 1984, João Pessoa. Atas do I Simpósio Nacional de História Antiga, 1983. p. 103-117.

NEUSTUPNÝ, E. Prerequisites of the archaeological method. In: Archaeological method. Cambridge University press, 1993. p. 20-43.

Ferramentas eletrônicas para o preparo de material visual:

Criador de plantas online. Floorplanner. Disponível em: http://www.floorplanner.com/ (acessado em 19 de maio de 2012).

Visualizador de mapas, imagens de satélite e vista panorâmica. Google Maps e Google Street View. Disponível em: https://maps.google.com.br/ (acessado em 19 de maio de 2012).

\section{AGRADECIMENTOS}

À Prof. Dr. Carolina Kesser Barcellos Dias, pela oportunidade de participar deste projeto, pela indispensável orientação e pela infindável paciência.

Ao Prof. Dr. Vagner Carvalheiro Porto, pelo cuidado e incentivo.

Ao Prof. Esp. Felipe Próspero, pelo auxílio, compreensão e atenção dispensados. 